\title{
A New Method for Promoting Critical Thinking in Online Education
}

\author{
http://dx.doi.org/10.3991/ijac.v7i4.4048 \\ Hisham Al-Mubaid \\ University of Houston - Clear Lake, Houston, USA
}

\begin{abstract}
The critical thinking process is a mental activity of actively and skillfully conceptualizing, applying, analyzing, synthesizing, and evaluating information to reach an answer or conclusion. It can also be viewed as a mental process that involves high quality and high level of thinking for problem solving and decision making. This paper presents and explains a new method for applying and promoting critical thinking for online education. The presented method can be applied in both online and regular classroom contexts, with being more practical and more appropriate for online education. The method consists of two components: an individual component and a team-based component. Each component includes a number of steps and the entire process is completed with a group setting. The Individual Component includes three steps:-List -Evaluate, and -Restructure; whereas the Team-based Component consists of three steps: -List, -Discuss and Evaluate, and -Integrate and Restructure. In each component, the learner is given essential opportunity to practice high level thinking and independent reasoning, and another chance to discuss and debate with other learners leading to an effective critical thinking medium. The method is straightforward to apply; and it guides students to practice and apply critical thinking to achieve quality learning and high level of understanding in the given learning task. This model has been applied and tested in both regular classroom setting and online education reaching satisfying and high levels of achieving critical thinking and intellectual growth among the learners.
\end{abstract}

Index Terms - Critical thinking, critical thinking in online education, applying critical thinking in online education.

\section{INTRODUCTION}

The critical thinking process is a sophisticated mental process that involves a high level of mental activity and extensive thinking to reach a reasonable solution, decision, or convergence acceptable to the mind. The formal definition states the critical thinking as the mental process of actively and skillfully conceptualizing, applying, analyzing, synthesizing, and evaluating information to reach an answer or conclusion [8,9]. The process of critical thinking is the process that leads to creativity in thinking and can be viewed as thinking and reasoning at its full strength. Teaching students how to think deeply while in their online course is one of the goals of this project with the main goal is to reach the highest level of quality thinking.

The interest in critical thinking started few decades ago and continued to increase as a part of research on learning and education. It has been found that critical thinking is very crucial for delivering quality learning in any subject and content area. Therefore, the learning and education research has invested extensively in critical thinking [1-5].

This paper presents a model and method for applying and promoting critical thinking for online education. This method can be applied in both online education and regular classroom contexts, but it is more practical for online education. The method is straightforward and fairly effective in teaching and leveraging critical thinking in both classroom and online education. The proposed method consists of two components: (1) Individual component: includes three steps: List, Evaluate, and Restructure. (2) Team-based component: consisting of three steps: List, Discuss/Evaluate, and Integrate/Restructure. The first step, List, in both components, implies that learners have to develop list of facts, concepts, or possible solutions that lead to problem solving or decision making. This list of facts, concepts, or possible solutions depends on the application domain and content area. In this paper, more details are given with examples of the proposed model using tasks that requires deep and high quality thinking leading to promoting critical thinking.

The first component is conducted by each student individually at his/her own pace and it is more suitable for online education. The second component, on the other hand, involves team-based work wherein the team meets online to list, discuss, evaluate, integrate and restructure their findings using the critical thinking approach. In each component, the learner is given an essential and inherent opportunity to practice high level thinking and independent reasoning. Furthermore, the learner will practice, in this model, high level form of critical thinking discussion and can debate with other learners, in the team, leading to effective critical thinking medium. The learning is attained in the first component by each learner with actively searching, analyzing, and evaluating information. The learning is attained in the second component collectively by the team through the high level of critical thinking discussions, debates, integrations, by the members of the team.

We applied, and we suggest applying, this method into team-based tasks that require deep thinking with inherent nature that fosters critical thinking. This model has been applied and tested on both regular classroom and online education settings reaching satisfying and high levels of achieving critical thinking among the learners.

\section{RELATED WORK}

Promoting and applying critical thinking into online education is of particular importance due to the high pace and wide spread of online education with the Internet revolution. The concept of critical thinking is a very old 
PAPER

A New Method for Promoting Critical Thinking In OnLine EduCATION

concept and the interest in it started long time ago. In the past few decades, however, we started experiencing more attention in integrating, augmenting, and applying critical thinking in education in many content areas and in various branches of science. The process of critical thinking can be seen as having two components, in the first component, a set of information and belief generating and processing skills. The second component involves the habit, based on intellectual commitment, of using those skills to guide behavior [1]. CriticalThinking.net defines critical thinking as reasonable reflective process of thinking focused on deciding what to believe or do [3]. In Saade et al. (2012), critical thinking is a type of a cognitive ability that has a special importance in decision making and judgment processes [14]. In general, three requirements are needed for critical thinking: - The learner understands the problem (questions, or concept) deeply so that the learner can be very close to a highly reasonable solution or answer. - The educator believes that the learner has gained a complete understanding of the problem or concept. -The learner has enough information that can be synthesized, arranged, and evaluated to reach high level of mental process of reasoning about the given concept. In a research study about critical thinking, by Paul, Elder, and Bartell [12], it was shown that an overwhelming majority $(89 \%)$ of university faculty claim that the promotion of critical thinking is a primary objective of their instruction. However, only $19 \%$ could define critical thinking and $77 \%$ had little, limited or no conception of how to reconcile content coverage with the fostering of critical thinking [12]. Another study by Bruning (2005) explains the role of critical thinking in online learning environments [6]. Some of the direct and tangible goals for the learner include:-to get in-depth understanding of the problem or concept. - to initiate and engage in quality discussion of the concept among students, and - to be able to develop different approaches to the solution. MacKnight (2000) proposes certain tools and strategies for applying critical thinking skill development in the online education settings [8]. In that article, MacKnight emphasizes on collaborative learning, reflection, peer editing, and monitored online discussions [8]. Boris and Hall (2005) present a research study with a group of graduate students in a graduate program on critical thinking [13]. Their study showed a major important change in the demonstrated critical thinking of the experimental group of graduate students after they were introduced to the practical inquiry model of Garrison et al. (2000) which is known as class intervention [13].

One of the closest projects to the proposed method is the work of Saade et al. (2012). They present the work and results of applying critical thinking in virtual learning environments. In that project, Saade et al. present and discuss a web-based course to assess critical thinking. The assessment is conducted to identify which is the most important part for achieving and promoting critical thinking [14]. Their results indicated the significance of interactivity in what student perceived to be critical thinking oriented versus online material as a resource [14].

\section{Proposed CRITICAL THINKING Method}

The method for applying and promoting critical thinking, proposed in this paper, can be applied in both regular classroom and online education settings; however, it is more practical in online education. The method involves most of the steps included in the process of critical think- ing: conceptualizing, applying, analyzing, synthesizing, and evaluation of information [8].

The method is fairly easy to apply in any educational setting and entails a good deal of quality learning and promoting critical thinking among the students. The method is applicable to team-based tasks in which the learners are given a task that involves learning and thinking

The method consists of two components:

- Individual component.

- Team-based component.These two components leads to applying and conducting effective critical thinking process and achieving quality learning through team based project involving several students.

\section{Individual component:}

The individual component consists of three steps:

-List, -Evaluate, and -Restructure.

In the first step, list, a learner will have to develop a list of facts, concepts, possible solutions, alternatives or pathways that lead to problem solving or decision making. The list depends on the application domain and content area. This step requires each learner to work individually on his/her own pace. For example, the concept of cell division (in biology) in utilized as learning task wherein each student will develop a short list of three to five items to explain the concept of cell division. Another example, from a computer networking course, is the concept of connection-oriented communication. The students, as teams, are given the assignment of explaining the concept of connection-oriented communication in computer networking. Each team is required to construct and develop a comprehensive and accurate definition and explanation of this concept. Yet another example, wireless sensor networks, where students are to explain and discuss this concept with critical thinking and deep learning. In these examples, the learner will have to collect, analyze, synthesize information about the target concept and this process comprise an important part of critical thinking.

In the second step, evaluate, each learner will evaluate the list of concepts developed in the first step. This includes ranking and scoring the items in the list developed in the first step. This involves a higher level mental activity and deeper thinking to evaluate and to weigh the items in the list. The items in the list of step one are basically the process of conceptualize, apply and synthesize the information while this second step allows for evaluate these items. The third step is an improvement on the second step through restructuring the components of the concepts developed in first two steps which includes revising and improving the understanding of the concept. This third step entails a high intellectual process.

\section{Team-based component:}

The team-based component includes three steps:

-List, -Discuss/Evaluate, and -Integrate/Restructure.

The first step is similar to that of the individual component except that it is done in groups here. In the teambased component, the list step requires the team as a whole to develop a comprehensive list of concepts, possible solutions, alternatives, or pathways that lead to problem solving or decision making for the problem. In the example above from biology, the team will collect and 
adapt their individual lists and produce one more accurate and more comprehensive list.

The second step: Discuss/Evaluate, the team members evaluate these possible solutions through information discussions focused on evaluating the items in the proposed list of the first step. MacKnight (2000) showed that engaging students into online discussions can contribute to their intellectual growth [8]

In the third step, Integrate and Restructure, the learners collectively integrate the ideas and restructure their possible solutions based on the discussions and debates of step two.

The first component is conducted by each student individually on his/her own pace and it is more suitable for online education. The second component, on the other hand, involves team-based work wherein the team meets online to list, discuss, evaluate, integrate and restructure their findings using the critical thinking approach. In each component, the learner is given an essential and inherent opportunity to practice high level thinking and independent reasoning. Furthermore, the learner will practice, in this model, high level form of critical thinking discussion and can debate with other learners, in the team, leading to critical thinking medium. The learning is attained in the first component by each learner actively searching, analyzing, and evaluating information. The learning is attained in the second component collectively by the team through the high level of critical thinking discussions, debates, integrations, by the members of the team.

We applied, and we suggest applying, this method into team-based tasks that require deep thinking with inherent nature that fosters critical thinking. This model has been applied and tested on both regular classroom and online education settings reaching satisfying levels of achieving critical thinking among the learners and instructors courses.

This model is straightforward and quite effective in teaching and leveraging critical thinking in both classroom and online education settings.

\section{APPLICATIONS AND EVALUATION}

The application of critical thinking in any learning task will lead to effective mental activity and high quality learning by following all the concepts of information conceptualization to synthesizing and evaluations. The presented methodology has been applied in several classroom settings in course projects and assignments that involve in-depth thinking and high learning curves. In this section we present and discuss four application cases of the proposed methodology in various classroom and learning settings.

-In programming course, students were given an assignment to write a report to discuss and explain the concept of using procedures in programming. This was done in two phases. In phase one, each student has to submit one- to two-page report with main goal of increasing student learning and understanding of this concept. In the second phase, students were divided into teams of four to five students per team. The instructor explains the method to students as explained in section III above and refers to critical thinking. The goal is to improve the learning and understanding through more in-depth thinking, analysis, and evaluation of the information.
Students are given one week to conduct the first component (individual component). The second week will be for the team component. Members of each team meet few times to go through the three steps of this component.

The instructor reviewed the deliverables of phase one and phase two. And students fill anonymous survey about their level of learning and understanding of the concept after phase two.

The results of this study were very encouraging. The instructor noticed significant improvement in student learning and understanding of the concept in phase two compared with phase one. Moreover, the survey results showed that students are highly satisfied of their high learning as result of phase two. The results are realistic and predictable that student achieved improvement in phase two but the contribution here is that the proposed method helped students and guided them through achieving high level of thinking and extensive mental activity that led to high level of quality learning in this particular study.

-In computer networking course, the students were asked to explain and discuss the concept of connectionoriented communication in the context of data communication and computer networking. The settings in this study was different that the first one. Students were asked to write a report of 700 to 1000 words to discuss and explain the concept of connection-oriented communication which is an important concept for learning data communication and computer networking. The students were asked to follow the method as explained in section III above and were divided into teams. For the first component of this method, each student should develop two to three alternatives. Each alternative is a possible solution to the problem. So each student has to develop two to three different possible definitions and explanations of the assignment concept. In the second component, each team meets and conducts the three steps of team-based component as discussed earlier.

To evaluate the level of learning and achieved critical thinking, the instructor review the deliverables and students fill anonymous survey that ask them direct questions about their perceived level of learning, quality of learning and level of critical thinking they attained from this assignment. The results again are very encouraging. All students are highly satisfied with their level of learning from this assignment and highly agree that they achieved good practice of critical thinking through this approach.

-In the third evaluation, the proposed critical thinking model was applied to class project in computer networking course. The assignment was to explain and clarify the concept and operation of the IP protocol. The IP protocol is the most important protocol in the Internet. It is actually, the unified and standard way of communication between computers in the Internet. As the previous two evaluations, students are to do this assignment using the critical thinking approach with its two components the individual component and team-based component. Students completed this project and submitted their deliverables with strong learning and deeper understanding of the concept. The conducted survey after this evaluation indicated that students highly agree with the fact that they learned more deeply and applied and practiced on critical thinking leading to high levels of reasoning and quality learning. 
-In other application studies for applying and promoting critical thinking, we used small learning tasks to engage students into critical thinking. For example, in one of these application studies, students were asked to summarize an important concept in the course that is covered in the textbook in one chapter. Students were divided into teams and each team has to develop a presentation slides that explain and summarize the chapter. Each presentation consists of ten slides that comprise the most important points about the concept. Students were instructed to answer question "What is concept-x?" by demonstrating strong knowledge and in-depth understanding of concept$x$ rather than just shallow explanations. Each member in the team should summarize three to five most important points in three to five slides for the first component. In the second component, the team-based component, the team members meet to discuss, debate, and evaluate their findings. Then they have to restructure and integrate their slides into a final list of points in ten slides. Students confirmed that they attained a good deal of quality learning and deeper critical thinking in working in this assignment.

In all these application cases, students were exposed to all phases of high quality learning and extensive mental process by exerting deep thinking, synthesizing, evaluating of knowledge and information.

\section{DISCUSSION AND CONCLUSION}

A number of learning tasks, including class team projects, and term paper assignments have been utilized for applying and promoting critical thinking among the students in the past few years using the proposed method. The method is straightforward to apply and can guide the learners to apply and practice of critical thinking for achieving high learning quality and deep understanding of the concepts in a given learning task. We explained the method and presented and discussed a number of application cases that proved the success of the method in promoting and enhancing deep thinking and solid learning leading to high levels of thinking, reasoning and understanding.

\section{REFERENCES}

[1] The Critical Thinking Community, official website; www.criticalThinking.org

[2] Bloom, B. S.; Engelhart, M. D.; Furst, E. J.; Hill, W. H.; Krathwohl, D. R. (1956). Taxonomy of educational objectives: The classification of educational goals. Handbook I: Cognitive domain. New York: David McKay Company.

[3] CriticalThinking.net: http://www.CriticalThinking.net

[4] Bloom, B. S. (1994). Reflections on the development and use of the taxonomy. In Rehage, Kenneth J.; Anderson, Lorin W.; Sosni- ak, Lauren A. "Bloom's taxonomy: A forty-year retrospective". Yearbook of the National Society for the Study of Education (Chicago: National Society for the Study of Education) 93 (2). ISSN 1744-7984.

[5] Pohl, M. (2000). Learning to Think, Thinking to Learn: Models and Strategies to Develop a Classroom Culture of Thinking. Cheltenham, Vic.: Hawker Brownlow. - See more at: http://www.nwlink.com/ donclark/hrd/bloom.html\#sthash.Iu3rhsr z.dpuf

[6] Bruning, K. (2005). The Role of Critical Thinking in the Online Learning Environment. International Journal of Instructional Technology and Distance Learning, 2(5).

[7] Anderson, L. W., Krathwohl, D. R., Airasian, P. W., Cruikshank, K. A., Mayer, R. E., Pintrich, P. R., Raths, J., Wittrock, M. C. (2000). A Taxonomy for Learning, Teaching, and Assessing: A revision of Bloom's Taxonomy of Educational Objectives. New York: Pearson, Allyn \& Bacon - See more at: http://www.nwlink.com/ donclark/hrd/bloom.html\#sthash.Iu3rhsr z.dpuf

[8] MacKnight, Carole (2000). Teaching Critical Thinking through Online Discussions. In Educause Quarterly. No. 4, 2000.

[9] Ennis, Robert H. (2011b). Critical thinking: Reflection and perspective Part II. Inquiry: Critical Thinking across the Disciplines, 26, 2 (Summer), 5-19.

[10] Ennis, Robert H. (2009). Investigating and assessing multiplechoice critical thinking tests. In Sobocan, J. and Groarke, L (Eds.), Critical thinking education and assessment: Can higher order thinking be tested? London, Ontario: Althouse. Pp. 75-97.

[11] Muirhead, Brent (2002). Integrating Critical Thinking into Online Classes. In U.S. Distance Learning Association USDLA Journal, Vol. 16, No. 11

[12] Paul, R.; Elder, L.; and Bartell, T. (1997). California Teacher Preparation for Instruction in Critical Thinking: Research Findings and Policy Recommendations: State of California, California Commission on Teacher Credentialing, Sacramento, CA, March 1997.

[13] Boris, G.; and Hall, T. (2005). Critical thinking and online learning: A practical inquirey perspective in higher education. 20th annual conference on distance teaching and learning.

[14] Saade, R. G.; Morin, D.; and Thomas; J. D. E. (2012). Critical thinking in E-learning environments. Computer in Human Behavior, Vol 28, No. 5. http://dx.doi.org/10.1016/j.chb.2012.03.025

[15] Akyüz, H. I., and Samsa, S. (2009). Critical thinking skills of preserve teachers in the blended learning environment. International Journal of Human Sciences, 6(2), 538-550.

\section{AUTHORS}

Hisham Al-Mubaid is with the University of HoustonClear Lake, Houston, TX, 77062 USA (e-mail: hisham@uhcl.edu).

This article is an extended and modified version of a paper presented at ICELW 2014, the Seventh Annual International Conference on Elearning in the Workplace, held from June 11-13, 2014 in New York. Submitted 15 July 2014. Published as resubmitted by the author 08 December 2014. 